Section Editors

David C. Spencer, MD

Steven Karceski, MD

\title{
Deep brain stimulation for Tourette syndrome
}

\section{$\underline{\underline{\underline{\underline{\underline{a}}}}}$}

Kevin J. Black, MD
WHAT IS TOURETTE SYNDROME? To discuss Tourette syndrome, one has to know what doctors mean by "tics." A tic is a brief, unwanted movement or noise that someone performs repeatedly, usually many times a day. Tics can be held back for a period of time, but this often brings a sense of building pressure to repeat the tic. Blinking, head shaking, and loud sniffing are common simple tics. More complex actions such as touching the floor or saying words can also be tics. Tics are very common: about a quarter of young children will have a tic for a short period of time, and about 1 child in each elementary school classroom has tics that last for a year or more. If a patient has both motor and vocal tics that started in childhood or teens, have lasted for at least a year, and do not have an identifiable specific cause, the patient receives a diagnosis of Tourette syndrome (TS).

By this accepted definition, TS is relatively common. Studies in which a large number of children are examined carefully for tics find that about 1 in 200 $(0.5 \%)$ have TS. However, only about half that number $(0.3 \%)$ have ever received the TS diagnosis. Only about a quarter of patients with TS describe their symptoms as moderate or severe. ${ }^{1}$ Thus most people with TS have fairly mild symptoms and are best managed with education and nonspecific supportive treatment. ${ }^{2}$

For others, however, TS is a daily battle. The problems can be many. There may be social problems like bullying in school or unfair treatment in job interviews. Children may have trouble concentrating in school because of tics or from focusing on holding tics back. Some patients have tics that are violent enough to cause injuries. It is appropriate to provide treatment for patients with any of these problems.

ARE EFFECTIVE TREATMENTS AVAILABLE FOR TS? Fortunately, there are a variety of treatments for tics. No available treatment cures TS, but 2 classes of treatment have proven effective after careful study. The first class consists of medicines that were originally developed to treat hallucinations. Recent drugs from this class, including risperidone, ziprasidone, olanzapine, and aripiprazole, reduce tics by about $50 \%$ on average. They are better tolerated than older drugs. The second kind of carefully stud- ied effective treatment is a type of behavior therapy. This was originally called habit reversal therapy and now, with changes, is called CBIT (Comprehensive Behavioral Intervention for Tics). ${ }^{3}$

Other treatments are available; in fact, more than 20 different kinds of treatment have been shown to be better than a placebo or "sugar pill." However, some patients with severe tics do not benefit enough or have side effects. For such patients even invasive treatments may be appropriate. One that has drawn much interest lately is deep brain stimulation (DBS).

WHAT IS DBS AND WHY WOULD IT BE APPLIED TO TS? Deep brain stimulation refers to placing very thin wires through the skull and into specific places in the brain, then sending electrical pulses through the wires to affect the activity of those brain regions. In other movement disorders, such as essential tremor or Parkinson disease, there is now good evidence that DBS is effective and relatively safe. This has led to the application of DBS to other movement disorders including TS.

Our state of knowledge regarding DBS for tics is no longer in its infancy but at best is still in the toddler stage. ${ }^{4}$ For one thing, it is not yet clear where in the brain the wires should be placed for best effect. The 2 best sites seem to be the internal globus pallidus (GPi) and the centromedian-parafascicular nuclei of the thalamus, near the middle of the brain (CM-Pf). Second, only a handful of patients with TS have participated in controlled studies of DBS, where active stimulation treatment is compared to sham or "pretend" treatment. ${ }^{5,6}$ Finally, little information is available on the long-term effects of DBS for tic disorders. ${ }^{7}$ The current study from Italy and the UK in this issue of Neurology ${ }^{\circledR}$ reports information on longterm DBS treatment in adults with TS. ${ }^{8}$

WHAT DOES THIS REPORT EXAMINE? Investigators examined 18 patients, aged 17-46 years, with severe TS that had not responded to simpler treatments. The patients had 2 years of DBS in the left and right CM-Pf. Two patients had asked for the DBS to be stopped. One needed a second surgery with DBS in a different location. The authors report on how DBS may have influenced thinking and be- 
havior in the remaining 15 patients. In addition to tics, patients with TS may have other behaviors including mood and anxiety problems. The authors used rating scales to assess the severity of tics, obsessions, compulsions, anxiety, depression, and social problems. They performed testing of attention, memory, and language. Information was collected monthly, but this report focuses on results at the 24month visit compared to before surgery.

WHAT WERE THE RESULTS? The 15 patients remaining in the study showed improvement in tics, obsessive-compulsive symptoms, depression and anxiety, and all but 1 had better scores on social functioning. None of the cognitive or "thinking" tests showed a bad effect of DBS, and in fact there was improvement in a measure of attention.

WHAT DO THESE RESULTS MEAN FOR PATIENTS? These results are good news for adults with severe TS who have not responded adequately to medications or behavior therapy. They suggest that the majority of patients treated with DBS in the CM-Pf will have improved symptoms without cognitive side effects after 2 years of treatment.

As the authors are careful to note, however, this report does not answer all questions about DBS for TS. It may not be successful in every patient. The 3 patients who dropped out of the study presumably did not have similar improvement. A few patients have been reported to have psychological side effects of DBS. It is considered a "Class IV" level of evidence (see "About levels of evidence").

When thinking of any treatment for TS, some important facts must be considered. None of the available tic treatments, including DBS, cures TS. Thus any treatment requires a careful weighing of the risks and benefits. Although DBS is relatively safe, it does carry some small risk of bleeding, infection, or injury. Half of children and teenagers with tics get better as they get older, to the point that as adults they no longer notice any tics. Furthermore, tics change in severity over time. Since DBS would probably be used when tics are at their worst, some improvement would be expected with or without DBS. However, the patients studied here had had severe tics for long periods of time, so improvement without treatment may be less likely.
For all these reasons, at this point DBS should be considered only for a small fraction of patients with TS. The Tourette Syndrome Association makes several recommendations about DBS: 1) Patients need to have full information about risks and benefits of DBS and about other available treatments. 2) Patients need a very thorough evaluation before surgery at centers with special expertise, to make sure that DBS is the most appropriate choice for each patient. 3) Until more information is available, most DBS for TS should be done in a clinical research setting in which the results will be shared quickly and widely. ${ }^{9}$

Future controlled studies are needed, but this report emphasizes that most patients with TS who receive treatment will have a good response without psychological side effects after 2 years of treatment with CM-Pf DBS.

\section{FOR MORE INFORMATION}

The Brain Matters

http://www.thebrainmatters.org

The Tourette Syndrome Association is a source of balanced information on treatment options for tics (bttp://www.tsa-usa.org/)

\section{REFERENCES}

1. Scahill L, Bitsko RH, Visser SN. Prevalence of diagnosed Tourette syndrome in persons aged 6-17 years - United States, 2007. MMWR Morb Mortal Wkly Rep 2009;58:581-585.

2. Black KJ. "Stop doing that!" Recognizing and managing tics. Mo Med 2008;105:53-56.

3. Woods DW, Piacentini JC, Chang SW, et al. Managing Tourette Syndrome: A Behavioral Intervention: Parent Workbook. New York: Oxford University Press; 2008.

4. Ackermans L, Temel Y, Visser-Vandewalle V. Deep brain stimulation in Tourette's syndrome. Neurotherapeutics 2008;5:339-344.

5. Maciunas RJ, Maddux BN, Riley DE, et al. Prospective randomized double-blind trial of bilateral thalamic deep brain stimulation in adults with Tourette syndrome. J Neurosurg 2007;107:1004-1014.

6. Welter ML, Mallet L, Houeto JL, et al. Internal pallidal and thalamic stimulation in patients with Tourette syndrome. Arch Neurol 2008;65:952-957.

7. Maddux B, Riley D, Whitney CM, Maciunas RJ. Doubleblind trial of thalamic DBS for Tourette syndrome: one-year follow-up. Neurology 2007;68(suppl 1):A155. Abstract.

8. Porta M, Brambilla A, Cavanna AE, et al. Thalamic deep brain stimulation for treatment-refractory Tourette syndrome: two-year outcome. Neurology 2009;73:1375-1380.

9. Mink JW, Walkup J, Frey KA, et al. Patient selection and assessment recommendations for deep brain stimulation in Tourette syndrome. Mov Disord 2006;21:1831-1838. 
Section Editors

David C. Spencer, MD

Steven Karceski, MD

\section{About levels of evidence}

Adapted from: Neurology Now 2009;5(2 March/ April):32-33.

Proof and Consequences, By Tom Valeo

The article on deep brain stimulation for Tourette syndrome (Neurology 2009;73:1375-1380) is considered a Class IV study. All studies in Neurology ${ }^{\circledR}$ are now rated on "levels of evidence." This allows the reader of the article to quickly get information about the quality of the study and to understand what problems might interfere with finding the "true answer" to a study question.

Doctors review scientific studies very carefully. There are many different kinds of studies. Although all of them can provide important information about medical illnesses, studies differ in the way that they are conducted. Some studies collect information in strict ways. The most stringent studies are referred to as randomized clinical trials or $R C T s$ and provide the least biased information. These are referred to as Class I. Trials that are not so strict still provide helpful information yet have been categorized with a lower class ranking (figure).

Figure Classification scheme requirements for therapeutic questions

\section{Classification scheme requirements for therapeutic questions}

Class I. A randomized, controlled clinical trial of the intervention of interest with masked or objective outcome assessment, in a representative population. Relevant baseline characteristics are presented and substantially equivalent among treatment groups or there is appropriate statistical adjustment for differences.

Class II. A randomized, controlled clinical trial of the intervention of interest in a representative population with masked or objective outcome assessment that lacks one criterion a-e in Class I or a prospective matched cohort study with masked or objective outcome assessment in a representative population that meets b-e in Class I. Relevant baseline characteristics are presented and substantially equivalent among treatment groups or there is appropriate statistical adjustment for differences.

Class III. All other controlled trials (including well-defined natural history controls or patients serving as their own controls) in a representative population where outcome is independently assessed or independently derived by objective outcome measurements.

Class IV. Studies not meeting Class I, II, or III criteria including consensus or expert opinion.
Class I: Referred to as RCTs, this kind of study is the most strict. People are selected for the study based on rigorous criteria that are developed even before the study begins. In this kind of study, patients are assigned randomly (in a sense, by "coin toss") to either a specific medical treatment or placebo (sometimes called a "sugar pill"). The person or team who rates how well patients do with the treatment cannot know whether the patient received the treatment or placebo: this is called "blinding." If the assessment team knows whether a patient is on placebo or treatment, it may influence their ratings. For example, they may (consciously or unconsciously) expect that patients on treatment will do better and patients on placebo will do worse. This could make a treatment appear better than it really is.

For instance, if a person's illness was improving, the treatment team may automatically-perhaps subconsciously-think that the treatment was successful because the patient received the treatment and not placebo. In other words, the fact that the treatment team does not know who received treatment takes away any influence that this knowledge could have on their assessments.

- The treatment team must not be aware which treatment the next study participant will receive until the participant has been enrolled and treatment has been assigned by someone else.

- The study team must decide their main question in advance of the study.

- There must be clear rules for who is included in the study and who cannot participate.

- At least $80 \%$ of people who enter the study must complete it.

- If a treatment is being compared to an existing "standard" treatment, certain strict rules must be followed.

Class II: A study that would be Class I except

- It lacks 1 of the above 5 points OR.

- It is a study that compares 2 groups of people that are similar except that 1 group received a treatment and the other did not. In this class, the treatment decision was made by the person's doctor and not randomly (not by "coin 
toss"). The person or team who rates how well patients did with the treatment should not know what treatment the patient received ("blinded").

Class III: Studies of all other types where the person or team rating the outcome is unaware of what treat- ment the person received ("blinded") or the outcome of the treatment can easily be measured in a standard way (for example, with a number) that does not require much judgment.

Class IV: Studies that do not meet the above rules including expert opinions. 


\section{Neurology}

\section{Deep brain stimulation for Tourette syndrome}

Kevin J. Black

Neurology 2009;73;e87-e90

DOI 10.1212/WNL.0b013e3181c284b3

\section{This information is current as of October 26, 2009}

\section{Updated Information \&} Services

References

Permissions \& Licensing

Reprints including high resolution figures, can be found at: http://n.neurology.org/content/73/17/e87.full

This article cites 7 articles, 1 of which you can access for free at: http://n.neurology.org/content/73/17/e87.full\#ref-list-1

Information about reproducing this article in parts (figures,tables) or in its entirety can be found online at:

http://www.neurology.org/about/about_the_journal\#permissions

Information about ordering reprints can be found online: http://n.neurology.org/subscribers/advertise

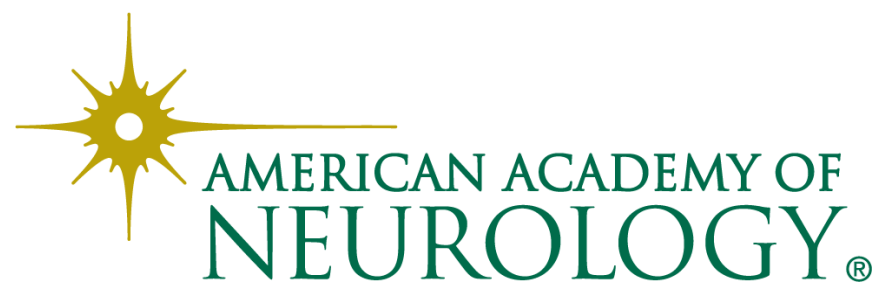

